\title{
Regional unemployment and norm-induced effects on life satisfaction
}

\author{
Adrian Chadi
}

\begin{abstract}
While rising unemployment generally reduces people's happiness, researchers argue that there is a compensating social-norm effect for the unemployed individual, who might suffer less when it is more common to be unemployed. This empirical study rejects this thesis for German panel data, however, and finds that individual unemployment is even more hurtful when regional unemployment is higher. On the other hand, an extended model that separately considers individuals who feel stigmatised from living off public funds yields strong evidence that this group of people does in fact suffer less when the normative pressure to earn one's own living is lower. A comprehensive discussion reconciles these findings with the existing research and concludes that to find evidence for the often described social-norm effect it is worthwhile to analyse disutility associated with benefit receipts.
\end{abstract}

Keywords Social norms · Regional unemployment · Individual unemployment . Well-being · Social benefits · Labour market policies

\section{Introduction}

The experience of unemployment is one of the most significant causes of unhappiness. Like individual unemployment, aggregate unemployment affects utility levels, but the effect is less clear. Studies using macroeconomic data report that higher levels of unemployment generally lead to lower levels of happiness among a population,

\footnotetext{
A. Chadi $(\varangle)$

The Institute for Labour Law and Industrial Relations in the European Union/IAAEU, University of Trier, 54286 Trier, Germany

e-mail: chadi@iaaeu.de
} 
which researchers refer to as the fear-of-unemployment effect (see, e.g., Tella et al. 2001, 2003). On closer examination, aggregate unemployment may affect everyone, but surely not in the same way. While, in the case of rising unemployment, employed individuals suffer from reduced job security (see, e.g., Luechinger et al. 2010), the unemployed undergo a different experience because they have no job to lose. At first glance, one could suggest that high unemployment rates have a particularly negative impact on the well-being of unemployed people, because the fewer the jobs available, the worse the prospects are for an end to the distressing situation. Interestingly, although this argument is mentioned in the happiness literature, the focus is primarily on a different connection between individual and aggregate unemployment. ${ }^{1}$

"Unemployment as a social norm" by Clark (2003) is certainly the most wellknown and oft-cited article in a research field in which it is argued that individual unemployment induces smaller reductions in well-being when more jobless persons are around. Using British panel data, Clark finds the well-being of the unemployed positively correlates with regional unemployment. ${ }^{2}$ This positive interaction between the two disutility determinants, individual and aggregate unemployment, is regarded as a social-norm effect, which refers to a specific attribute commonly associated with norms. Because norm conformity is determined by the level of conformity among those considered relevant others, the level of normative pressure to comply with a specific norm often varies substantially between social groups or regions (see, e.g., Elster 1989a; Young 2008). Based on this notion, researchers conjecture (regional) differences in the disutility caused by norm violation, which then can be interpreted as evidence for the effect of a social norm. In concrete terms, non-compliance with the norm leads to greater unhappiness in regions with generally greater norm adherence, whereas normative pressure and corresponding effects on norm violators are weaker when fewer people adhere to the norm, so that norm violation is more common.

In the meantime, there are a number of empirical studies about this happinessincreasing interaction between the effects of individual and aggregate unemployment (e.g., Powdthavee 2007; Shields and Wheatley Price 2005, Shields et al. 2009). More recently, after reproducing this finding with German panel data (see Clark et al. 2009), Clark et al. (2010) go a step further by introducing a more complex model that they expect to be promising in yielding evidence for a social-norm effect. While this obviously raises questions about potential shortcomings of the standard approach, it is noteworthy that the authors integrate information about job prospects into their analysis. For certain, using a model with only one interaction variable, it can be very difficult to examine the impact of the social norm when there are potential counter effects also linked to regional unemployment levels. Although it may mitigate the distress when one's own unemployment is not an isolated incident, increasing unemployment simultaneously affects the prospects of getting out of the misery, which might be even

\footnotetext{
1 For general surveys in happiness research, see, e.g., Frey and Stutzer (2002, 2005), Frey (2008) and Van Praag and Ferrer-i-Carbonell (2008). Studies specifically investigating the disutility effects of individual unemployment include those of Clark and Oswald (1994), Winkelmann and Winkelmann (1998), Carroll (2007), Chadi (2010) and Knabe and Rätzel (2011).

2 While Clark (2003) also examines the role of unemployment among other reference groups, namely, unemployment at the partner and household levels, the discussion in this study focuses only on the relationship between individual unemployment and others' unemployment at the regional level.
} 
more painful than the general fear-of-unemployment effect experienced by the still employed. If this is a significant argument, then the empirical researcher is indeed confronted with two countervailing effects that cannot be identified by a model with only one interaction between the disutility factors individual and aggregate unemployment. In order to solve this problem, this paper proposes a novel approach that refers to the original understanding of the social norm to be examined, as a norm against dependency on others.

In their empirical study of regional differences in unemployment-induced unhappiness, Stutzer and Lalive (2004) refer to philosopher and social scientist Elster (1989b, p. 121) for a definition of the norm they are out to investigate: "There is a social norm against living off other people and a corresponding normative pressure to earn one's income from work." At first glance, one might deduce that violation of such a norm is equivalent to being unemployed. However, the social norm against living off other people could also be violated in the case of employed individuals who receive social benefits in addition to their earned income when they otherwise would have less than the subsistence level. ${ }^{3}$ Hence, it is quite possible to distinguish between unemployment and norm violation at the individual level, at least in countries where potentially stigma-laden benefits are paid to more than just the unemployed. Chadi (2012) builds upon this distinction by identifying in German panel data the disutility effect of dependency on public funds, an effect that while significant is not as great as unemployment-induced reductions in well-being. The benefit dependency effect is on average slightly more than 0.1 points on the 11 -point life-satisfaction scale. The unemployment effect, meanwhile, is found to be well greater than 0.4 points of satisfaction loss, a finding in line with previous research. The study also examines whether there are differences related to the recipients' employment status. One major finding is the indication that working people may actually suffer as norm violators when they receive benefits, which is an important contribution to policy debate about labour market concepts. Based on the average impact of these effects, the author concludes that individuals with jobs requiring supplemental benefits appear to be better off overall than those without any job at all. However, if the argument is indeed valid, and people are suffering from stigmatisation due to non-compliance with a social norm, then these average effects may in fact hide the full extent of the problem of benefit dependency. The disutility effects from receiving benefits may be much greater in regions where normative pressure is strong, unlike in other regions that have become used to this social phenomenon. Since Chadi (2012) only focuses on average effects for the country as a whole, a subsequent research objective is to explore regional variations. Such a differentiation between regions offers two major opportunities to complement existing research. First, the examination of a potential link between measures for regional norm strength, and the disutility effects of benefit dependency offers further evidence for reconsidering the current understanding of the norm against living off others. Second, by comparing these results with the findings from the standard unemployment-centric approach, a deeper understanding of social norms and their potential role in the labour market can be reached.

\footnotetext{
3 Note that, for reasons of simplicity, and in accordance with the original definition of the social norm, the term "living off other people" is used throughout the paper despite its negative connotations.
} 
To properly construct a comparison of different disutility effects, it is essential to distinguish not only between unemployment and norm violation among individuals, but also between unemployment and norm violation at an aggregate level. Stutzer and Lalive (2004) provide an example, showing how the norm aspect can be separated from the issue of unemployment at the regional level. Utilising the results of a Swiss referendum, they argue that votes in favour of a reduction in unemployment benefits can be connected to the belief that it is not right to live off public funds. Thus, the higher the regional percentage of voters approving the benefit cut, the stronger the social norm, which is thereby measured not by unemployment rates, as it is usually done. The insertion of a separate measure for norm strength allows the information about unemployment rates to be used for a different purpose, which in this paper is to capture the impact of varying job prospects on unemployed people's well-being. Consequently, the empirical study focuses on multiple interactions to yield convincing evidence for the social-norm effect. On the one hand, the utility effect of the interaction between aggregate and individual unemployment is expected to yield a negative outcome, demonstrating the unhappiness-increasing impact of worsening job prospects on unemployed people in particular. On the other, the interaction between the strength of the social norm in a region and individual non-compliance with the norm, which is the case for those living off public funds, is expected to demonstrate the norm effect, implying that stronger/weaker normative pressure leads to larger/smaller reductions in well-being for those violating the norm.

The paper proceeds as follows. Section 2 offers information on the data and the empirical framework, including a discussion of how to determine norm violation at the individual level and how to find potential measures for the strength of the social norm at the regional level. Section 3 gives the empirical results, which are interpreted and discussed in Sect. 4, including their potential implications for labour market policies. Section 5 concludes.

\section{Data and empirical framework}

The dataset used in this empirical investigation covers the period from 1999 to 2009 and comes from the German Socio-Economic Panel Study (SOEP), a large representative survey of German households (see Wagner et al. 2007). In the SOEP questionnaire, respondents evaluate their general life satisfaction on a scale ranging from 0 ("completely dissatisfied") to 10 ("completely satisfied"), which then can be used as a proxy for individual utility levels. Since changes in life satisfaction are triggered by a series of relevant factors, such as differences in income, this study conducts a multiple regression analysis that includes a control set of factors potentially determining individual well-being to isolate unemployment-induced disutility effects as well as the impact of being in non-compliance with the norm against living off other people.

One of the most important factors influencing well-being levels is the time-invariant personality trait, which results from genetic inheritance (see Lykken and Tellegen 1996; Neve et al. 2012). From a methodological perspective, this suggests the use of fixed-effects models that take into account these given, but unobservable, factors (see, e.g., Frijters et al. 2004; Knabe and Rätzel 2011). In their methodological discussion, 
Ferrer-i-Carbonell and Frijters (2004) argue that the consideration of fixed individual effects is indeed substantial and likely to be more important than the ordinality of the life satisfaction responses. Hence, the standard ordinary least squares (OLS) method is certainly an appropriate tool in happiness research, although economists, in particular, have always been rather reluctant to interpret satisfaction data as cardinal. In order to address scepticism of this sort and to confirm the robustness of the findings, the standard OLS method is supplemented here by the use of the (Van Praag and Ferrer-i-Carbonell 2008) probit-adjusted ordinary least squares (POLS) method. Before running the regression, POLS requires a transformation of the discrete happiness scores into values on the real axis by considering the actual sample distribution. Since interaction variables play a major role in the empirical analysis, the POLS method is regarded here as superior to non-linear regression models with their well-known pitfalls (see Ai and Norton 2003).

Analysing the interaction between unemployment-induced disutility effects and aggregate unemployment levels is rather simple from a technical perspective. For the latter, publicly available data from the German Employment Office is used. In concrete terms, aggregate unemployment is the annual unemployment rate at the (federal) state level in Germany. ${ }^{4}$ On the other hand, the measurement of the regional strength of the social norm, as well as the precise distinction between individuals in compliance with the norm and those violating it, requires a detailed discussion, especially against the background of the given social system in the country to be examined.

\subsection{Individual (non-) compliance with the social norm}

The analysis of the isolated disutility from being dependent on public funds can be very difficult when those receiving benefits are also unemployed. Fortunately, from the perspective of the empirical researcher, and although both groups do of course overlap to a significant extent, it is quite possible to distinguish between benefit recipients and unemployed individuals in Germany. Accordingly, by controlling for other influencing factors of individual life satisfaction, the isolated effect of being unemployed can be separated from the effect of non-compliance with the norm against dependency on others. In a second step, these effects can be further investigated with respect to how they vary regionally. Prior to that, however, it is necessary to determine what types of benefits can actually be considered norm relevant, i.e., the receipt of which benefits puts someone in the group of those potentially stigmatised for being in non-compliance with the norm.

Since this question has been addressed in a recent study quite comprehensively, the discussion here focuses on the most important aspects and refers to the empirical evidence found previously (see Chadi 2012). First, it is critical to disregard unemployment insurance benefits in the context of the social norm against living off others. The theoretical justification for this stems from the particular nature of the so-called

\footnotetext{
4 As can be seen in Table 2, the division of Germany into regions in this study differs (slightly) from the official classification of the German federal states. Note that, in contrast to the SOEP data, the available unemployment data are not reported separately for East and West Berlin. On the other hand, the federal states of Rhineland-Palatinate and Saarland are not reported separately by the SOEP.
} 
"Arbeitslosengeld" (ALG), which individuals receive for a limited period from the quasi-governmental unemployment insurance after becoming unemployed. Because of its configuration as a payment from an insurance system, into which the unemployed individual has previously contributed on a mandatory basis, it is plausible to expect a different public perception compared to the people's views on those benefits that are known to be taxpayer-funded. While recipients of benefits such as social assistance are often regarded as those who are indeed living off other people, ALG benefits are rather seen as a citizen's right (Lindbeck 1995, p. 481). In fact, empirical evidence confirms that the unemployed in general do not feel additionally stigmatised by receiving unemployment insurance benefits, so the investigation here focuses on a bundle of other benefits for which stigma effects can be found..$^{5}$

In Germany, a variety of different benefits can be linked to potential stigma effects, suggesting their receipt to be a violation of the norm against living off public funds. For a few years, "Arbeitslosengeld II" (ALG2) has been the social system's major component. Up to 2004, unemployed persons received unemployment assistance after their limited period of ALG receipts, but this old follow-up benefit programme was subsequently merged with the social assistance programme into the dominant transfer scheme ALG2 as part of major labour market reforms. Note that eligibility is calculated on a household basis, which is very important to the investigation here. ${ }^{6}$ Furthermore, ALG2 is specifically targeted at low-income earners when the household income is below a certain level. Because of this option of topping up low earnings, ALG2 guarantees a minimum level of income not only for the unemployed, but also for some of those actually working.

Further relevant types of social benefits for which households in Germany can be eligible are housing assistance, social assistance, and basic protection for the elderly or those with a reduced capacity to work, the latter having been paid since 2005 . Concerning the unemployment assistance, as the predecessor of ALG2, it must be mentioned that this benefit was determined on an individual rather than a household basis. However, because most benefits are not paid to individuals, the best way to distinguish between those who comply with the social norm against living off public funds and those who do not is to compare households. Hence, the group of norm violators consists of individuals living in households that receive at least one of the above-mentioned benefits.

For each year and each category, Table 1 gives observation numbers in the SOEP data sample, which consists of 123,239 observations from 24,371 (either employed or unemployed) individuals aged 18-65 who lived and stayed in one region during the entire period of investigation. It makes sense to exclude individuals who moved from one state to another during the period of investigation, so that the regionally varying implications from norm violation are not biased by mover-caused effects. The categories of interest in this study are unemployed registered individuals (UE)

\footnotetext{
5 In addition to the primary source of empirical evidence for the line of argument here (Chadi 2012), Kassenboehmer and Haisken-DeNew (2009) find that the receipt of social assistance in Germany can lead to reductions in people's well-being.

6 To be precise, the law defines persons as either directly eligible or as part of a "Bedarfsgemeinschaft", which, in order to reduce complexity, is treated here as a regular household.
} 
Table 1 Observation numbers for each category

\begin{tabular}{lrrrrr}
\hline Year & \multicolumn{1}{l}{ EMP } & \multicolumn{1}{l}{ UE } & \multicolumn{1}{c}{ SN } & UE $\times$ SN & \multicolumn{1}{c}{ ALL } \\
\hline 1999 & 7,029 & 862 & 679 & 342 & 7,891 \\
2000 & 11,719 & 1,327 & 1,025 & 597 & 13,046 \\
2001 & 10,683 & 1,221 & 886 & 531 & 11,904 \\
2002 & 11,720 & 1,228 & 850 & 527 & 12,948 \\
2003 & 10,673 & 1,293 & 942 & 586 & 11,966 \\
2004 & 10,266 & 1,265 & 1,026 & 637 & 11,531 \\
2005 & 9,755 & 1,224 & 986 & 627 & 10,979 \\
2006 & 10,178 & 1,308 & 1,212 & 798 & 11,486 \\
2007 & 9,762 & 1,056 & 1,025 & 672 & 10,818 \\
2008 & 9,245 & 875 & 885 & 553 & 10,120 \\
2009 & 9,587 & 963 & 921 & 605 & 10,550 \\
& 110,617 & 12,622 & 10,437 & 6,475 & 123,239 \\
\hline
\end{tabular}

$E M P$ individuals who are employed either full-time or part-time; $U E$ individuals who are registered as unemployed; $S N$ individuals living in households in which at least one individual receives one of the following as norm related identified benefits: unemployment assistance ("Arbeitslosenhilfe"), ALG2 ("Arbeitslosengeld 2"), social assistance ("Sozialhilfe"), housing assistance ("Wohngeld"), basic protection for the elderly or those with a reduced capacity to work ("Grundsicherung im Alter und bei Erwerbsminderung")

Data: SOEP waves from 1999 to 2009 with individuals aged 18-65

and those living in households that receive benefits classified as relevant to the social norm against living off other people (SN). While relevant numbers of unemployed people receive ALG or even do without any of the previously mentioned payments, about half of them live in benefit-receiving households, so that the groups of the unemployed and those violating the norm logically overlap $(\mathrm{UE} \times \mathrm{SN})$. Nevertheless, in the context of the given national social system, this segregation into two categories is obviously feasible at the individual level. Similarly, the analysis of norm strength at the regional level requires a thorough discussion of the issue of measurement as well.

\subsection{The strength of the social norm at the regional level}

There are several ways to determine the strength of a social norm in a given region. One is to establish people's beliefs, i.e., what they actually think about the behavioral rule to be examined. A widely popular method, though, is to use information about people's actual behaviour, for which, according to researchers, the unemployment rate can be utilised as a proxy. For the reasons given earlier, it is considered inappropriate to use the unemployment rate per region as the measure for normative pressure. Instead, the interplay between individual norm conformity and strength of the social norm needs to be separated from the one between individual and aggregate unemployment, for which unemployment rates are better used. Hence, a separate measure for the regional strength of the social norm must be found for the empirical analysis. 
Table 2 Regional levels of unemployment and strength of the social norm

\begin{tabular}{|c|c|c|c|c|c|}
\hline Region & $\begin{array}{l}\text { Mean } \\
\text { unemployment } \\
\text { in \%** }\end{array}$ & 1. Behavior & $\begin{array}{l}\text { 2. Social } \\
\text { views }\end{array}$ & 3. Religiosity & $\begin{array}{l}\text { Geometric } \\
\text { mean } \\
\text { values }\end{array}$ \\
\hline Saxony-Anhalt* & 19.78 & 18.84 & 36.12 & 80.24 & 37.94 \\
\hline Mecklenburg-Vorpommern* & 19.39 & 19.59 & 33.04 & 76.63 & 36.74 \\
\hline West Berlin & 18.56 & 17.22 & 30.98 & 74.48 & 34.12 \\
\hline East Berlin* & 18.56 & 13.17 & 38.23 & 86.83 & 35.23 \\
\hline Brandenburg* & 18.09 & 20.07 & 35.41 & 81.61 & 38.71 \\
\hline Saxony* & 18.01 & 16.91 & 31.55 & 74.47 & 34.12 \\
\hline Thuringia* & 16.17 & 19.46 & 32.75 & 73.08 & 35.98 \\
\hline Bremen & 14.57 & 11.92 & 40.30 & 61.77 & 30.96 \\
\hline Hamburg & 10.81 & 6.82 & 33.46 & 66.52 & 24.76 \\
\hline North Rhine-Westphalia & 10.79 & 8.62 & 32.53 & 49.45 & 24.02 \\
\hline Lower Saxony & 10.47 & 7.92 & 33.30 & 51.47 & 23.85 \\
\hline Schleswig-Holstein & 10.23 & 11.15 & 29.61 & 52.61 & 25.90 \\
\hline Hesse & 8.69 & 6.10 & 34.08 & 49.11 & 21.69 \\
\hline $\begin{array}{l}\text { Rhineland-Palatinate/ } \\
\text { Saarland }\end{array}$ & 8.54 & 8.74 & 30.83 & 45.08 & 22.99 \\
\hline Bavaria & 6.87 & 5.06 & 26.12 & 38.90 & 17.26 \\
\hline Baden-Wuerttemberg & 6.32 & 6.03 & 31.94 & 43.34 & 20.29 \\
\hline
\end{tabular}

Explanation of the measures for norm strength: (1) Behavior: weighted percentage of individuals in the data sample not conforming with the social norm against living off benefits (according to the classification in Table 1), (2) social views: geometric mean of (a) the weighted percentage of individuals who do not regard social security contributions as too high (in the year 2002) and (b) the weighted percentage of individuals seeing only the state as responsible for providing financial security in the case of unemployment (in the year 2002), (3) religiosity: weighted percentage of individuals who attend neither church nor religious events (in the year 2001)

* Former GDR regions

Data: German Employment Office (**); SOEP waves from 1999 to 2009

A first and simple idea for a norm proxy suggests itself thanks to the novel design of this investigation. When individual unemployment and norm violation are not regarded as one and the same, the aggregation of norm violation at the state level is in fact the observed group behavior commonly used as a proxy. Accordingly, for every region, the weighted percentage of people living in benefit-receiving households, and thus not complying with the norm, is determined for the entire period and given in the second column of Table 2. In accordance with the common interpretation of the unemployment rate as a norm proxy, a higher percentage of norm violation reflects a weaker norm.

As mentioned above, Stutzer and Lalive (2004) suggest capturing people's beliefs about the social norm in a more direct way, instead of using group behavior as a proxy. Since their idea to look at differences in the views on social security seems quite plausible, similar information is used to generate a second norm measure here. In the year 2002, SOEP participants were asked, "Do you think the social security contributions or premiums that you pay are too high, appropriate or too low?" In line 
with the Stutzer and Lalive argument, it can be assumed that the more people in a state favour the first answer and regard their contribution as too high, the stronger the pressure to earn one's own living for each citizen of that region. The same SOEP questionnaire from 2002 offers a further opportunity to capture people's beliefs about the financing of social security. By responding that "financial security in the case of unemployment" is a private rather than a public responsibility, people may signal a stronger belief that it is wrong to live off public funds. Accordingly, the percentage of responders demanding that only the state is responsible indicates the weakness of the norm. Presented in the third column of Table 2, the data on the two questions are merged into a norm measure by determination of the geometric mean values for each state. Note that for the sake of comparability, larger numbers again indicate weaker normative pressure.

Another aspect often associated with social norms is religiosity. In his study on benefit morale, Heinemann (2008) suggests, in reference to other empirical studies, that people who are more religious generally might hold in higher esteem morality and norm-guided behavior. This positive correlation is particularly found in studies on tax morale, indicating that religiosity supports the enforcement of social norms (e.g., Torgler 2005; Alm and Torgler 2006). Therefore, the idea is to use information about church attendance to generate a third potential measure for the strength of the social norm. Based on SOEP data from 2001, the weighted percentage of people who attend neither church nor religious events is used as a norm proxy and is given in the fourth column of Table 2 .

Given the difficulties of empirical research on social norms, the use of different measures for the strength of the social norm should make it possible to obtain valid findings. In addition to the regression models for each separate measure, a further model in this investigation uses one derived from the information of all three, i.e., aggregate norm behavior, views on social security and level of religiosity. Accordingly, for each region, the geometric mean of these three values is formed and presented in the last column of Table 2. Corresponding to the short period of time on which this study focuses, the strength of a norm is considered constant. Hence, these given norm values are actually used in the empirical analysis, in contrast to the average unemployment rates that are shown in the first column. In fact, the state unemployment rates in the econometric models vary from year to year simply because employment prospects are expected to do so as well.

\subsection{East-west disparity}

A closer look at regional unemployment rates reveals a fundamental economic disparity between East and West Germany, even after the many years since reunification (see Table 2). Regarding the objective of comparing the effects of varying job prospects on individual well-being, the consideration of this basic difference may be relevant to building a properly specified regression model. When the regional unemployment rate is set in relation to the unemployment-induced disutility effect, this initially implies that, even in well-performing eastern regions, the unemployed may perceive their situation to be more hopeless than in economically weak regions in the West. Hence, 
the use of an additional interaction variable for being unemployed in one or the other half of Germany is expected to yield significant outcomes and thereby increase the accuracy of the specification. The same disparity problem could exist in regard to the norm strength measure, especially when the level of norm behavior is captured on the basis of benefit receipts in each region.

A retrospective view of the two different systems in Germany, prior to 1990, reveals further support for the idea of additional interaction variables capturing the basic differences in the norm-and unemployment-induced disutility effects. Since social norms are formed and determined by "norm senders" that can also have an institutional character (Lindbeck and Nyberg 2006), it is important to note that, according to Article 24 of the constitution of the GDR, there was not only a right to work, but also a duty to work in East Germany. In practice, despite enormous differences in economic status, nearly everyone could earn a living from work in the socialist half of Germany, whereas in the West more and more citizens suffered unemployment. Following reunification, unemployment has become a reality in the eastern states, but certainly the perception has never been the same. While the view of unemployment as the unemployed person's own fault is expected to be more widespread in societies with a free-market tradition, the East German tradition would rather allow pushing at least some responsibility onto the state and the government, which previously ensured full employment. On the other hand, in view of the constitutional duty to work, the individual contribution to the common good is more likely to be perceived as an obligation of each citizen. Not being in compliance with social duties, such as the social norm against living off others, could therefore be seen as more of an offense in the eastern regions.

One might argue that these considerations are irrelevant to this study because of the many years between the fall of the GDR and the period investigated. However, empirical research on German people's attitudes and beliefs support the notion of a prolonged disparity between East and West in regard to the issues to be examined here (e.g., Alesina and Fuchs-Schündeln 2007). Hence, while the above considerations lead to the expectation of an additional disutility effect of norm violation in the East, a significant disutility effect of being unemployed in the western states would indicate a stronger perception of unemployment as the unemployed person's own failure.

\subsection{Empirical strategy}

The above considerations lead to the definition of an empirical model for the analysis of whether and how disutility from non-conformity with the norm against living off others varies with the regional strength of the norm, while unemployment-induced disutility is expected to increase with rising unemployment and thereby worsening job prospects. Such a model constitutes an extension of what has been proposed in the literature. Nevertheless, it is perhaps very revealing to first leave out the novel elements designed to isolate norm effects from the impact of changing job prospects and to look at the results of the Clark model that has been implemented in most of the previous studies:

$$
\mathrm{LS}_{i t}=\alpha_{i}+\beta_{1} \mathrm{UE}_{i t}+\beta_{2} \mathrm{~L}_{i t}+\beta_{3}\left(\mathrm{UE}_{i t}{ }^{*} \mathrm{~L}_{i t}\right)+\gamma^{\prime} \mathrm{X}_{i t}+\mu_{t}+\varepsilon_{i t}
$$


In line with Clark et al. (2009), life satisfaction $\left(\mathrm{LS}_{\mathrm{it}}\right)$ is explained by a set of variables, including individual unemployment $\left(\mathrm{UE}_{\mathrm{it}}\right)$ and regional unemployment at the state level $\left(\mathrm{L} 1_{\text {it }}\right)$. The idea is that empirical evidence for a "social norm of unemployment"effect is found when the variable for the interaction between the latter two disutility determinants is positive, so that higher regional unemployment implies overall less disutility from being unemployed. Referring to the previous subchapter, a first modification to the model seems necessary when investigating German panel data. In order to consider the prolonged disparity between East and West, the data sample can be split into two separate ones or, alternatively, additional interaction terms can be used. Following the latter, the main model of the present study also integrates variables representing the novel understanding of the social norm to be examined:

$$
\begin{aligned}
\mathrm{LS}_{i t}= & \alpha_{i}+\beta_{1} \mathrm{UE}_{i t}+\beta_{2} \mathrm{~L}_{i t}+\beta_{3}\left(\mathrm{UE}_{i t}{ }^{*} \mathrm{~L}_{i t}\right)+\beta_{4}\left(\mathrm{UE}_{i t}{ }^{*} \mathrm{EAST}_{i}\right) \\
& +\beta_{5} \mathrm{SN}_{i t}+\beta_{6}\left(\mathrm{SN}_{i t}{ }^{*} L 2_{i}\right)+\beta_{7}\left(\mathrm{SN}_{i t}{ }^{*} \mathrm{EAST}_{i}\right)+\gamma^{\prime} \mathrm{X}_{i t}+\mu_{t}+\varepsilon_{i t}
\end{aligned}
$$

Here, a dummy variable for individual non-compliance with the norm against living off public funds $\left(\mathrm{SN}_{\mathrm{it}}\right)$, an interaction with the measure for time-invariant norm strength at the state level $\left(\mathrm{L} 2{ }_{\mathrm{i}}\right)$, and interactions with a dummy variable for living in regions of the former GDR (EAST ${ }_{\mathrm{i}}$ ) are added to the standard model. ${ }^{7}$ While $\alpha_{\mathrm{i}}$ is the individual fixed effect, $\mu_{\mathrm{t}}$ is the year effect, and $\varepsilon_{\mathrm{it}}$ is the error term, the set of further factors influencing life satisfaction $\mathrm{X}_{\mathrm{it}}$ includes variables for employment status, marital status, number of children, health, age, German nationality, individual income level as well as timevarying GDP per capita at the state-level.

\section{Results}

The regression analyses on the basis of the models presented in the previous section should be prefaced with some descriptive evidence to illustrate the paper's main argument. As demonstrated by related studies (e.g., Winkelmann and Winkelmann 1998), an investigation of the average changes in life satisfaction that go along with changes in labour market status has proved to be informative in this context. Since the objective here is to examine regional differences in the disutility effects from unemployment and benefit receipts, such a transition analysis must be based on data from two separate samples, so that a comparison can take place. In order to illustrate the identification of different groups in the labour market but also to look for first evidence, the two samples compared in Table 3 are states with low levels of norm strength and states with high levels of norm strength (according to the values presented in the last column of the above Table 2) within each of the former halves of Germany. Technically, the average levels for each half are used to divide all states into two groups (above- and below-average), which is in line with including an interaction term for the general difference between East and West in the analysis.

In contrast to previous investigations of unemployment-related norm effects, this paper emphasizes the role of those individuals, whether unemployed or not, who

\footnotetext{
7 Note that the model considers the above assumption of no migration between regions.
} 


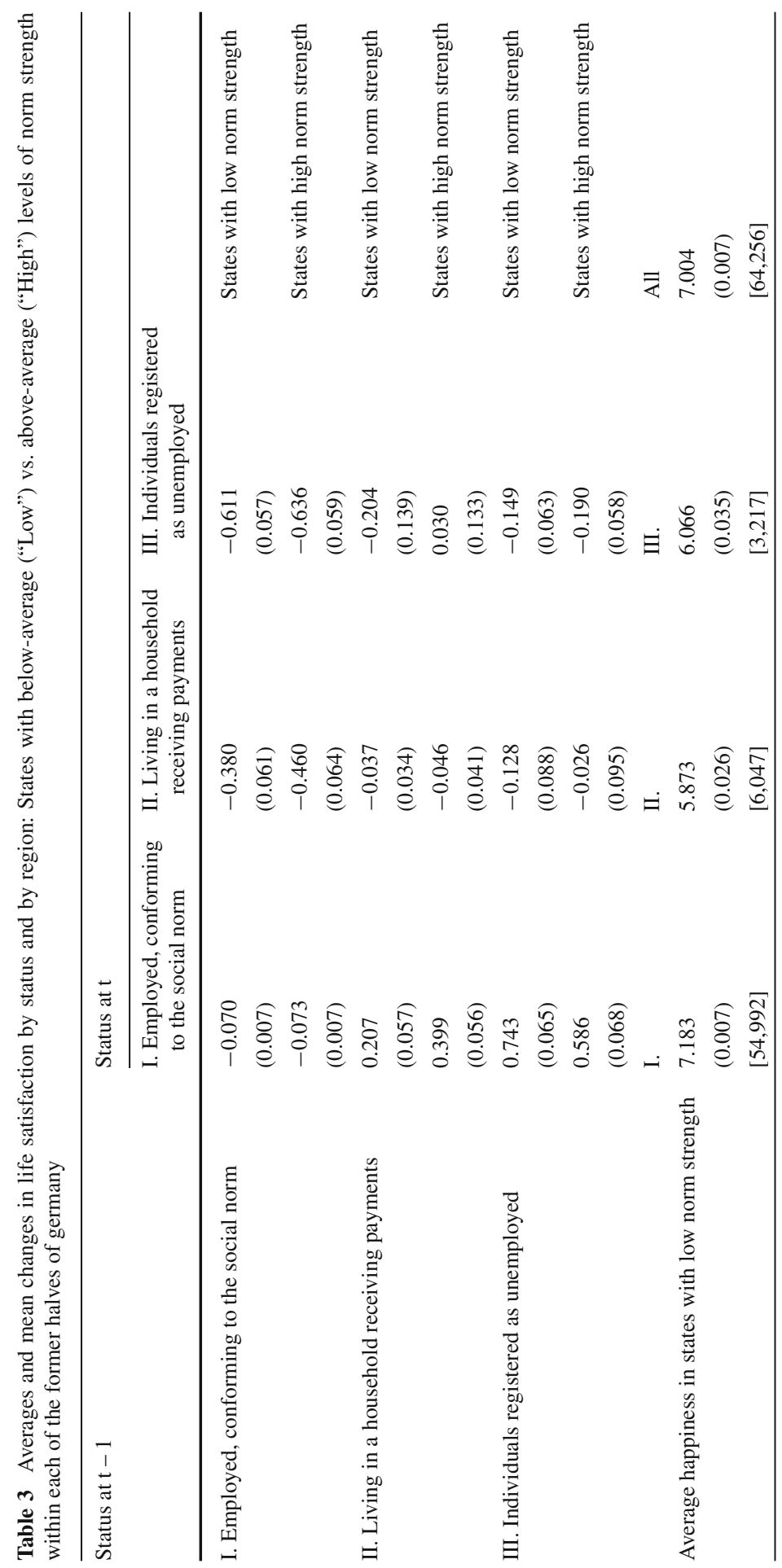




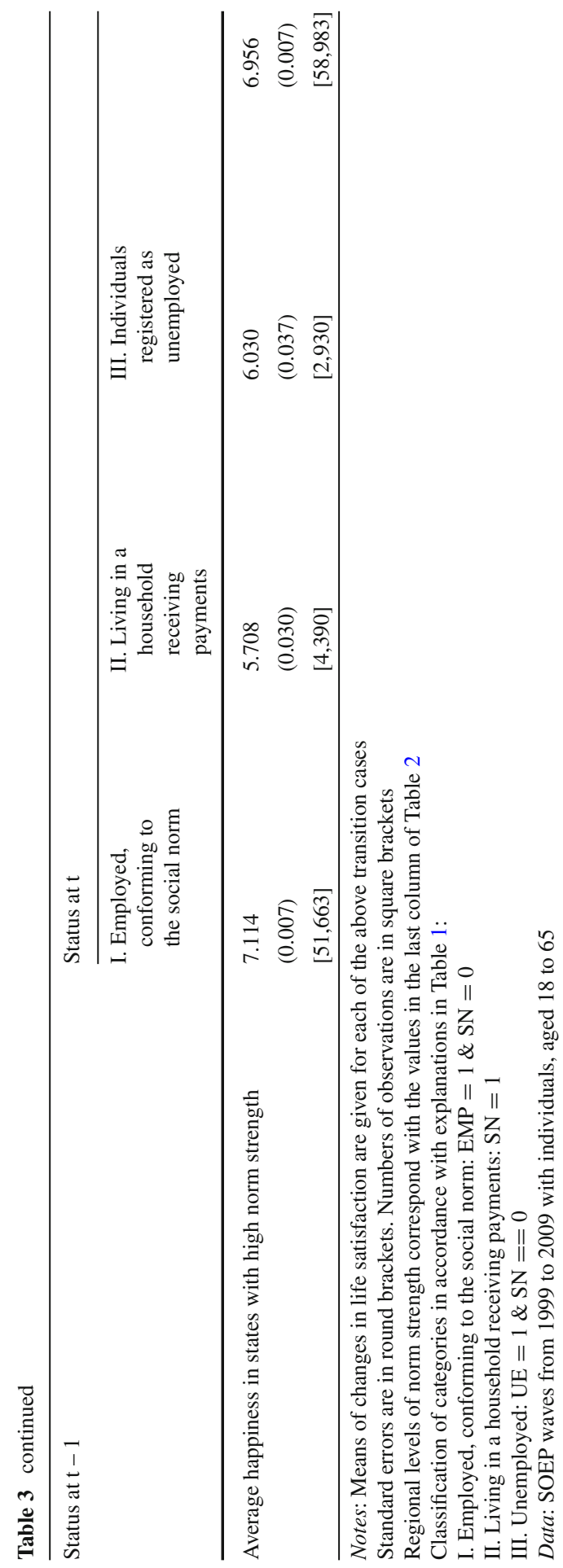


are living in households that are dependent on potentially stigmatising benefits. This group appears as category II in the descriptive illustration of Table 3 and is completely separated here from those unemployed who are not receiving such social benefits (category III). The comparison of status changes concerning benefit receipts points to the potential role of a social norm against living off public funds. Indeed, for the people in states with high norm strength, compared to those living in the other states, switching from employment that is in line with this social norm (category I) to the status of being in a benefit-dependent household is associated with stronger reductions in life satisfaction. ${ }^{8}$ Vice versa, the transition to the status of norm compliance appears to be a much more positive event, indicating that it is more important for people to comply with the norm against living off public funds when there is a stronger normative pressure. In fact, the mean increase in life satisfaction scores is almost twice as large (0.399 compared to 0.207$)$.

An alternative analysis that is not subject to the East-West issue compares the two most populous German federal states, North Rhine-Westphalia (NRW), and Bavaria (see Table 7 in the Appendix). ${ }^{9}$ Interestingly, while Bavarians in benefit-receiving households are on average unhappier than their counterparts in NRW, the opposite is true for the unemployed non-recipients. In fact, the only reason that all the Bavarians taken together are on average slightly happier in the data used here is the comparatively happy lot of unemployed people, which, because of the low unemployment rates in Bavaria, contrasts with the standard understanding of the relationship between individual unemployment and aggregate unemployment. In addition, leaving unemployment appears to be a much more positive event in NRW, while the average decrease in satisfaction for those becoming unemployed in Bavaria is generally smaller, which also raises the question of whether it is really a norm against unemployment that is affecting people. Prior to the introduction of the norm against benefit receipts, regressions on the basis of the standard model should aid comprehension of the connection between this paper's line of argument and the findings in previous studies.

\subsection{The Clark model}

The regression analysis starts without separate norm measures, either at the individual or at the aggregate level, but with only one variable for the interaction between individual and aggregate unemployment, which is, according to Clark and other researchers, capable of demonstrating the social-norm effect. Based on the notion that being unemployed may be less hurtful when more people around are in the same situation, it is argued that empirical evidence for this is found when the variable for the interaction between the disutility determinants, individual and aggregate unemployment, is positive. Table 4 gives the results of the implementation of this standard model, which, according to the literature, should show that higher regional unemployment implies overall less disutility from being unemployed. Nevertheless, it is quite intriguing that

\footnotetext{
8 Recall that higher levels of norm strength are expressed in smaller values in Table 2.

9 Note that Bavaria is associated with very strong norms (see Table 2), whereas NRW appears to be average in regard to unemployment and norms.
} 
Table 4 Regional differences in the disutility effects of individual unemployment

\begin{tabular}{|c|c|c|c|c|c|c|}
\hline \multirow{3}{*}{$\begin{array}{l}\text { Territory } \\
\text { Method } \\
\text { Dependent variable }\end{array}$} & \multicolumn{2}{|l|}{ All Germany } & \multicolumn{2}{|c|}{ Only Western Regions } & \multicolumn{2}{|c|}{ Only Eastern Regions } \\
\hline & OLS FE & POLS FE & OLS FE & POLS FE & OLS FE & POLS FE \\
\hline & \multicolumn{2}{|c|}{ Life satisfaction } & \multicolumn{2}{|c|}{ Life satisfaction } & \multicolumn{2}{|c|}{ Life satisfaction } \\
\hline $\begin{array}{l}\text { UE: Individual } \\
\text { unemployment }\end{array}$ & $\begin{array}{l}-0.518 * * * \\
(0.033)\end{array}$ & $\begin{array}{l}-0.259 * * * \\
(0.018)\end{array}$ & $\begin{array}{l}-0.718 * * * \\
(0.088)\end{array}$ & $\begin{array}{l}-0.367 * * * \\
(0.045)\end{array}$ & $\begin{array}{l}-0.262 * * \\
(0.098)\end{array}$ & $\begin{array}{l}-0.115^{* *} \\
(0.043)\end{array}$ \\
\hline $\begin{array}{l}\text { L1: Level of } \\
\text { unemployment }\end{array}$ & $\begin{array}{l}-0.025^{* * * *} \\
(0.008)\end{array}$ & $\begin{array}{l}-0.018 * * * \\
(0.004)\end{array}$ & $\begin{array}{l}-0.015 \\
(0.014)\end{array}$ & $\begin{array}{l}-0.014 \\
(0.008)\end{array}$ & $\begin{array}{l}0.074 * * \\
(0.026)\end{array}$ & $\begin{array}{l}0.039 * * \\
(0.011)\end{array}$ \\
\hline Interaction term $(\mathrm{UE} \times \mathrm{L} 1)$ & $\begin{array}{l}-0.010^{* *} \\
(0.005)\end{array}$ & $\begin{array}{l}-0.004 * \\
(0.002)\end{array}$ & $\begin{array}{l}-0.016 \\
(0.024)\end{array}$ & $\begin{array}{l}-0.009 \\
(0.011)\end{array}$ & $\begin{array}{l}-0.026 \\
(0.025)\end{array}$ & $\begin{array}{l}-0.015 \\
(0.011)\end{array}$ \\
\hline Gender & Both & Both & Only men & Only men & Only men & Only men \\
\hline Controls & Yes & Yes & Yes & Yes & Yes & Yes \\
\hline Observations & 123,239 & 123,239 & 50,388 & 50,388 & 15,527 & 15,527 \\
\hline Adjusted $\mathrm{R}^{2}$ & 0.1175 & 0.1119 & 0.1339 & 0.1252 & 0.1217 & 0.1141 \\
\hline
\end{tabular}

Notes: $*$ denotes significance at the $10 \%$ level, $* *$ at the $5 \%$ level and $* * *$ at the $1 \%$ level

Controls include variables for employment status, marital status, number of children, health, age, German nationality, individual income level, year dummies as well as regional GDP per capita. Clustered standard errors (by region) are in parentheses. Unemployment rates are de-meaned

Data: SOEP waves from 1999 to 2009 with employed and unemployed individuals aged 18-65

the OLS method results, presented in the first column, include a significant interaction coefficient of -0.010 , suggesting that the unemployed suffer even more and not less, when aggregate unemployment is higher. Using the POLS method, this coefficient is less significant, but still negative.

As a matter of fact, this result, as striking as it may look, is not necessarily a contradiction of the previous research. In some studies, including those based on German data, the norm effect has been found only for men. Indeed, a restriction on male persons would lead to a positive, albeit insignificant interaction between regional unemployment levels and unemployed people's well-being, just as in the Clark et al. (2010) study. However, in addition to the lack of theoretical foundation for these essential gender differences and the unsubstantiated notion that only men are affected by such a norm, there is another problem with this finding. As can be seen in the last four columns of Table 4, once the data are split into a western and an eastern sample, there is no social-norm effect at all, not even for men. Note that the outcomes show sizeably different utility effects for East and West, which further substantiates the need for a differentiated analysis. Moreover, note that only by disregarding the disparity between the two former halves of Germany is it possible to find significant positive outcomes for the interaction between individual and aggregate unemployment. ${ }^{10}$

10 This is also confirmed by additional regressions on the basis of data from the same period of time (1984-2006) as in the Clark et al. studies. Using the same methods and controls, their "social norm of unemployment"-effect (found only for men) disappears as soon as the data is restricted to the western German regions. 


\subsection{The Extended model}

Nevertheless, this study's objective is not to disprove the relevance of social norms, but to give more conclusive empirical evidence by presenting a comprehensive model that makes it possible to distinguish between the disutility caused by individual unemployment and the disutility of not complying with a norm against living off other people. For the latter, a second interaction term can be formed using the measures for the strength of the social norm that are described in Section 2. Hence, Table 5 presents the results for aggregate norm behavior, views on social security, and level of religiosity as norm proxy variables. In fact, the interaction between these measures and individual norm violation (Interaction term 3) is positive throughout the specifications. Thanks to the norm measures being generated analogous to the unemployment rates, so that lower values imply higher levels of norm strength, this finding corresponds to the notion of a positive social-norm effect, for which researchers seek to deliver convincing evidence. People suffer less from not being in conformity with the norm the weaker the norm strength and thus the more norm violation takes place. In contrast, the interaction between individual and aggregate unemployment (Interaction term 1) is negative in all models, showing that the people experience additional distress from being unemployed when unemployment levels are high.

Closer examination of these specifications, which according to the above argument also include further interaction terms for being unemployed in the East (Interaction term 2) and individual norm violation in the East (Interaction term 4), reveals some differences concerning the use of each separate measure of norm strength. To begin with, aggregate behavior, measured by the share of norm violators in each region, seems highly appropriate to capture norm effects in this empirical framework. In fact, the interaction between individual norm violation and level of norm strength is in all specifications significant at the 5\% level. The findings are very similar when using religiosity as a proxy for the norm strength. In the OLS regression, the extended model with all four interaction terms shows a positive norm effect that is significant at the $5 \%$ level. Generally, it seems useful to include an interaction term for non-compliance in the eastern regions when using religiosity as a norm proxy. As can be seen in Table 2, there is no such East-West disparity in the values of the social-beliefs measure, which is consistent with the fourth interaction term being insignificant for both methods, while the interaction between individual norm violation and norm strength is more significant in specifications without additional interaction terms (see Table 8 in the Appendix). Certainly, the fourth interaction variable seems most important when using aggregate norm violation as a proxy for the strength of the norm at the regional level. As argued above, the very different percentage numbers of norm violators and unemployed individuals in East and West already suggest the need for additional interaction terms, apart from the social-historical reasoning. In fact, the variable for being unemployed in the eastern regions is significant throughout the specifications, and, thanks to its integration, the significance of the first interaction between individual and aggregate unemployment becomes considerably stronger. This can be interpreted as further evidence for all four interaction terms being necessary, while it again demonstrates the neg- 
Table 5 Regional differences in the disutility effects of individual unemployment and non-compliance with the social norm: Separate measures for the strength of the norm

\begin{tabular}{|c|c|c|c|c|c|c|}
\hline \multirow{3}{*}{$\begin{array}{l}\text { Norm Proxy } \\
\text { Method } \\
\text { Dependent variable }\end{array}$} & \multicolumn{2}{|c|}{ Aggregate behavior } & \multicolumn{2}{|c|}{ Social security beliefs } & \multicolumn{2}{|l|}{ Religiosity } \\
\hline & OLS FE & POLS FE & OLS FE & POLS FE & OLS FE & POLS FE \\
\hline & \multicolumn{2}{|c|}{ Life satisfaction } & \multicolumn{2}{|c|}{ Life satisfaction } & \multicolumn{2}{|c|}{ Life satisfaction } \\
\hline $\begin{array}{l}\text { UE: Individual } \\
\text { unemployment }\end{array}$ & $\begin{array}{l}-0.493 * * * \\
(0.034)\end{array}$ & $\begin{array}{l}-0.250 * * * \\
(0.017)\end{array}$ & $\begin{array}{l}-0.493 * * * \\
(0.034)\end{array}$ & $\begin{array}{l}-0.251 * * * \\
(0.017)\end{array}$ & $\begin{array}{l}-0.493 * * * \\
(0.034)\end{array}$ & $\begin{array}{l}-0.250 * * * \\
(0.017)\end{array}$ \\
\hline $\begin{array}{l}\text { L1: Level of } \\
\text { unemployment }\end{array}$ & $\begin{array}{l}-0.021 * * \\
(0.008)\end{array}$ & $\begin{array}{l}-0.015 * * * \\
(0.004)\end{array}$ & $\begin{array}{l}-0.021 * * \\
(0.008)\end{array}$ & $\begin{array}{l}-0.015^{* * *} \\
(0.004)\end{array}$ & $\begin{array}{l}-0.021 * * \\
(0.008)\end{array}$ & $\begin{array}{l}-0.015 * * * \\
(0.004)\end{array}$ \\
\hline $\begin{array}{l}\text { Interaction term } 1 \\
\quad(\mathrm{UE} \times \mathrm{L} 1)\end{array}$ & $\begin{array}{l}-0.036 * * * \\
(0.012)\end{array}$ & $\begin{array}{l}-0.019 * * * \\
(0.006)\end{array}$ & $\begin{array}{l}-0.035^{* *} \\
(0.012)\end{array}$ & $\begin{array}{l}-0.018 * * * \\
(0.006)\end{array}$ & $\begin{array}{l}-0.036^{* * * *} \\
(0.012)\end{array}$ & $\begin{array}{l}-0.019 * * * \\
(0.006)\end{array}$ \\
\hline $\begin{array}{c}\text { Interaction term } 2 \\
(\mathrm{UE} \times \mathrm{EAST})\end{array}$ & $\begin{array}{l}0.323 * * \\
(0.119)\end{array}$ & $\begin{array}{l}0.186 * * * \\
(0.056)\end{array}$ & $\begin{array}{l}0.311 * * \\
(0.122)\end{array}$ & $\begin{array}{l}0.181 * * * \\
(0.056)\end{array}$ & $\begin{array}{l}0.326 * * \\
(0.121)\end{array}$ & $\begin{array}{l}0.187 * * * \\
(0.057)\end{array}$ \\
\hline $\begin{array}{l}\text { SN: Individual } \\
\text { non-compliance }\end{array}$ & $\begin{array}{l}-0.140 * * * \\
(0.030)\end{array}$ & $\begin{array}{l}-0.072 * * * \\
(0.018)\end{array}$ & $\begin{array}{l}-0.138 * * * \\
(0.026)\end{array}$ & $\begin{array}{l}-0.070 * * * \\
(0.015)\end{array}$ & $\begin{array}{l}-0.138 * * * \\
(0.031)\end{array}$ & $\begin{array}{l}-0.070 * * * \\
(0.018)\end{array}$ \\
\hline $\begin{array}{l}\text { Interaction term } 3 \\
\quad(\mathrm{SN} \times \mathrm{L} 2)\end{array}$ & $\begin{array}{l}0.032 * * \\
(0.011)\end{array}$ & $\begin{array}{l}0.015 * * \\
(0.006)\end{array}$ & $\begin{array}{l}0.023 * * \\
(0.009)\end{array}$ & $\begin{array}{l}0.011^{*} \\
(0.005)\end{array}$ & $\begin{array}{l}0.010 * * \\
(0.004)\end{array}$ & $\begin{array}{l}0.004 * \\
(0.003)\end{array}$ \\
\hline $\begin{array}{l}\text { Interaction term } 4 \\
(\mathrm{SN} \times \mathrm{EAST})\end{array}$ & $\begin{array}{l}-0.290^{* *} \\
(0.121)\end{array}$ & $\begin{array}{l}-0.129 * \\
(0.068)\end{array}$ & $\begin{array}{l}-0.004 \\
(0.037)\end{array}$ & $\begin{array}{l}0.004 \\
(0.020)\end{array}$ & $\begin{array}{l}-0.258^{*} \\
(0.124)\end{array}$ & $\begin{array}{l}-0.102 \\
(0.073)\end{array}$ \\
\hline Controls & Yes & Yes & Yes & Yes & Yes & Yes \\
\hline Observations & 123,239 & 123,239 & 123,239 & 123,239 & 123,239 & 123,239 \\
\hline Adjusted $\mathrm{R}^{2}$ & 0.1181 & 0.1124 & 0.1181 & 0.1124 & 0.1181 & 0.1124 \\
\hline
\end{tabular}

Notes: $*$ denotes significance at the $10 \%$ level, $* *$ at the $5 \%$ level and $* * *$ at the $1 \%$ level

Controls are as in Table 4. Clustered standard errors (by region) are in parentheses. Classification of the social norm (SN) category is in accordance with the explanations in Table 1. Regional levels of norm strength (L2) correspond with the values in the three middle columns of Table 2 and are assumed to be constant over the period of investigation, so they are not included in the fixed-effects models. Unemployment rates and regional levels of norm strength are de-meaned. The indicator variable EAST is 1 in the case of the former GDR regions (see Table 2) and 0 otherwise

Data: SOEP waves from 1999 to 2009 with employed and unemployed individuals aged 18-65

ative effect from rising unemployment on the well-being of unemployed men and women.

Similar insights can be obtained from regressions based on the fourth measure for the strength of the social norm. Taken from the last column of Table 2, the geometric mean values can be regarded as another norm proxy, which integrates the information from all other measures. ${ }^{11}$ Accordingly, the results in the first two columns of Table 6 again confirm that the unemployed suffer additionally from higher levels of regional unemployment (Interaction term 1) and that living off public funds is less distressing in regions with weaker normative pressure to earn one's own living (Interaction term 3 ). A comparison of these coefficients with those found in a smaller model (see the first two columns of Table 9 in the Appendix) also shows that these relationships are even

\footnotetext{
11 Note that the geometric mean makes more sense compared to the arithmetic mean, since the latter would give more weight to outliers with large values. According to some additional regressions, the outcomes are nevertheless quite similar in both cases, so that the main findings are not affected by this aspect anyway.
} 
Table 6 Regional differences in the disutility effects of individual unemployment and non-compliance with the social norm: Generated measure for the strength of the norm

\begin{tabular}{|c|c|c|c|c|c|c|}
\hline $\begin{array}{l}\text { Method } \\
\text { Dependent variable }\end{array}$ & $\begin{array}{l}\text { OLS FE } \\
\text { Life satisfa }\end{array}$ & $\begin{array}{l}\text { POLS FE } \\
\text { action }\end{array}$ & $\begin{array}{l}\text { OLS FE } \\
\text { Life satisfac }\end{array}$ & $\begin{array}{l}\text { POLS FE } \\
\text { action }\end{array}$ & $\begin{array}{l}\text { OLS FE } \\
\text { Life satisfac }\end{array}$ & $\begin{array}{l}\text { POLS FE } \\
\text { ction }\end{array}$ \\
\hline UE: Individual unemployment & $\begin{array}{l}-0.493 * * * \\
(0.034)\end{array}$ & $\begin{array}{l}-0.250 * * * \\
(0.017)\end{array}$ & $\begin{array}{l}-0.508 * * * \\
(0.032)\end{array}$ & $\begin{array}{l}-0.262^{* * * *} \\
(0.017)\end{array}$ & $\begin{array}{l}-0.492 * * * \\
(0.034)\end{array}$ & $\begin{array}{l}-0.255^{* * * *} \\
(0.017)\end{array}$ \\
\hline L1: Level of unemployment & $\begin{array}{l}-0.021 * * \\
(0.008)\end{array}$ & $\begin{array}{l}-0.015^{* * *} \\
(0.004)\end{array}$ & $\begin{array}{l}-0.021 * * \\
(0.008)\end{array}$ & $\begin{array}{l}-0.015^{* * * *} \\
(0.004)\end{array}$ & $\begin{array}{l}-0.021 * * \\
(0.008)\end{array}$ & $\begin{array}{l}-0.015^{* * * *} \\
(0.004)\end{array}$ \\
\hline Interaction term 1 (UE x L1) & $\begin{array}{l}-0.037 * * * \\
(0.012)\end{array}$ & $\begin{array}{l}-0.019 * * * \\
(0.006)\end{array}$ & $\begin{array}{l}-0.032 * * \\
(0.012)\end{array}$ & $\begin{array}{l}-0.017 * * \\
(0.006)\end{array}$ & $\begin{array}{l}-0.037 * * * \\
(0.012)\end{array}$ & $\begin{array}{l}-0.019 * * * \\
(0.006)\end{array}$ \\
\hline Interaction term 2 (UE x EAST) & $\begin{array}{l}0.333^{* *} \\
(0.122)\end{array}$ & $\begin{array}{l}0.190 * * * \\
(0.057)\end{array}$ & $\begin{array}{l}0.313 * * \\
(0.120)\end{array}$ & $\begin{array}{l}0.179 * * * \\
(0.056)\end{array}$ & $\begin{array}{l}0.329 * * \\
(0.118)\end{array}$ & $\begin{array}{l}0.191 * * * \\
(0.056)\end{array}$ \\
\hline SN: Individual non-compliance & $\begin{array}{l}-0.144 * * * \\
(0.022)\end{array}$ & $\begin{array}{l}-0.073 * * * \\
(0.014)\end{array}$ & $\begin{array}{l}-0.165^{* * *} \\
(0.036)\end{array}$ & $\begin{array}{l}-0.090 * * * \\
(0.020)\end{array}$ & $\begin{array}{l}-0.142^{* * * *} \\
(0.037)\end{array}$ & $\begin{array}{l}-0.080^{* * * *} \\
(0.021)\end{array}$ \\
\hline Interaction term 3 (SN x L2) & $\begin{array}{l}0.027 * * * \\
(0.007)\end{array}$ & $\begin{array}{l}0.012 * * \\
(0.004)\end{array}$ & $\begin{array}{l}0.029 * * * \\
(0.007)\end{array}$ & $\begin{array}{l}0.014 * * * \\
(0.004)\end{array}$ & $\begin{array}{l}0.026 * * * \\
(0.008)\end{array}$ & $\begin{array}{l}0.012 * * \\
(0.005)\end{array}$ \\
\hline Interaction term 4 (SN x EAST) & $\begin{array}{l}-0.325^{* * * *} \\
(0.104)\end{array}$ & $\begin{array}{l}-0.141 * * \\
(0.063)\end{array}$ & $\begin{array}{l}-0.313^{* * *} \\
(0.098)\end{array}$ & $\begin{array}{l}-0.133 * * \\
(0.060)\end{array}$ & $\begin{array}{l}-0.324 * * * \\
(0.103)\end{array}$ & $\begin{array}{l}-0.140 * * \\
(0.063)\end{array}$ \\
\hline Interaction term 5 (UE x SN) & & & $\begin{array}{l}0.057 \\
(0.060)\end{array}$ & $\begin{array}{l}0.044 \\
(0.029)\end{array}$ & $\begin{array}{l}-0.004 \\
(0.059)\end{array}$ & $\begin{array}{l}0.018 \\
(0.029)\end{array}$ \\
\hline \multicolumn{3}{|l|}{ Interaction term $6(\mathrm{UE} \times \mathrm{SN} \times \mathrm{L} 1)$} & $\begin{array}{l}-0.011 \\
(0.008)\end{array}$ & $\begin{array}{l}-0.006 \\
(0.004)\end{array}$ & & \\
\hline Interaction term 7 (UE x SN x L2) & & & & & $\begin{array}{l}0.002 \\
(0.007)\end{array}$ & $\begin{array}{l}-0.000 \\
(0.003)\end{array}$ \\
\hline Controls & Yes & Yes & Yes & Yes & Yes & Yes \\
\hline Observations & 123,239 & 123,239 & 123,239 & 123,239 & 123,239 & 123,239 \\
\hline Adjusted $\mathrm{R}^{2}$ & 0.1182 & 0.1124 & 0.1182 & 0.1124 & 0.1181 & 0.1124 \\
\hline
\end{tabular}

Notes: $*$ denotes significance at the $10 \%$ level, $* *$ at the $5 \%$ level and $* * *$ at the $1 \%$ level

Controls are as in Table 4. Clustered standard errors (by region) are in parentheses. Classification of the social norm ( $\mathrm{SN}$ ) category is in accordance with the explanations in Table 1. Regional levels of norm strength (L2) correspond with the values in the last column of Table 2 and are assumed to be constant over the period of investigation, so they are not included in the fixed-effects models. Unemployment rates and regional levels of norm strength are de-meaned. The indicator variable EAST is 1 in the case of the former GDR regions (see Table 2) and 0 otherwise

Data: SOEP waves from 1999 to 2009 with employed and unemployed individuals aged 18-65

more marked when additional interaction terms are used for being unemployed in the eastern regions (Interaction term 2) and being in non-compliance with the social norm in the eastern regions (Interaction term 4).

Note that for those unemployed individuals living in benefit-receiving households, the two opposing interaction effects must be offset against each other. Hence, the significant additional disutility effect from higher unemployment can be compensated for in terms of general life satisfaction when living off public funds is a smaller deviation from the norm. Before the coefficients can be added for the purpose of interpretation, however, it is first necessary to check whether the disutility effects 
are indeed similar or whether there are significant differences in the effects for this intersection group. Accordingly, in the final four columns of Table 6, a variable that represents unemployed recipients of social benefits (Interaction term 5) is shown not to be significantly different from zero, suggesting no general difference in the implications for satisfaction levels. ${ }^{12}$ In addition, there is no evidence of significant differences in regional variation of the utility effects (Interaction term 6, Interaction term 7). Hence, the main findings are similar for the intersection group of unemployed people in benefit-receiving households, which facilitates the results' interpretation.

\subsection{Robustness checks}

There are a number of robustness checks that one may consider, but not all can be reported here. To begin with, restrictions in the data sample could be relaxed, which refers to the focus on only employed and unemployed individuals as well as the removal of all those who moved from one region to another during the period of investigation. Although these restrictions make a lot of sense, for instance, to allow a comparison of more homogenous groups of people, results for a larger data sample are very similar.

Besides, the main regressions, discussed in the previous subchapter, make use of additional interaction terms to deal with the disparity between western and eastern regions. While this ensures the amenities of a data set that is as large as possible, the alternative is to run regressions on data from each of the former halves of Germany separately. In this case, the functional form of the regressions is allowed to be different, which facilitates another check of the main interactions and their robustness. Again, there is evidence for a happiness-decreasing interaction between the effects of individual and aggregate unemployment, whereas disutility from non-compliance with the norm against living off others is indeed related to the level of norm strength in the way described in the literature on social norms (see the final four columns of Table 9 in the Appendix).

Another aspect worth examining is the measurement of norm strength at the regional level. First note that the norm proxies used in this study can approximate, but can never be exact measures of, the normative pressure to earn one's own living. With respect to the level of religiosity, the question on church attendance has been part of the SOEP questionnaire more than once, so further robustness checks are possible. While the findings are the same throughout all the regressions, the statistical significance of the results differs, and as a result the interaction between individual norm violation and norm strength is in some cases more significant, while in others less so. A measure of religiosity, generated on the basis of all available information on church attendance, yields results similar to those presented here.

12 Thanks to the de-meaning of norm strength levels and unemployment rates, the coefficient for each group can be interpreted as a mean effect for inhabitants of regions with average unemployment and average normative pressure. Hence, in line with the literature, the OLS outcomes indicate the unemployment-induced disutility to be about 0.5 points on the life satisfaction scale, and benefit receipts on average slightly more than 0.1 points. 
Regarding the social-beliefs measures, extensive robustness checks are possible by use of data from other sources. While there are dozens of potentially relevant questions included in one social survey alone, the sensitivity analysis conducted here is based on several of those alternative sources of data. ${ }^{13}$ By way of example, the focus of this segment is on the first few items from the Eurobarometer surveys that can be selected on similar grounds as the SOEP-based measures. Assuming, for instance, that more support for government expenditures on social welfare goes along with a weaker normative pressure to earn one's own income, regional norm proxies can be generated in the same vein as above. In a subsequent step, these variables can be used for the purpose of additional regression analyses (see Table 10 in the Appendix). ${ }^{14}$ Whereas all of these estimations indicate that weaker norm strength is related to higher levels of well-being among benefit recipients, not every proxy leads to a significant outcome. In fact, the comprehensive comparison of proxies from multiple data sources shows that there is a substantial amount of variation in such variables, and consequently in the estimated norm effects calculated on the basis of such measures. Remarkably, even almost identical queries within the same interviews can lead to dissimilar outcomes. ${ }^{15}$ In many of these cases, it is likely that other survey factors affect interviewee responses and the measurement of social norms. A more general explanation for this may lie in the small number of observations when regional comparisons are carried out. It is also important to note that despite the large number of seemingly fitting proxies, none exactly reflect the norm examined in the paper. Nevertheless, a simple approach to all of these problems can be the averaging of several measures to gather a more stable one. In the case of these Eurobarometer proxies, this does indeed lead to a significant norm effect (see the last column of Table 10 in the Appendix).

Overall, the sensitivity analysis with norm measures from alternative social surveys confirms the paper's argument. Certainly one can argue that, in comparison with social-beliefs measures, the objective information on regional differences in people's actual behavior as well as the religiosity proxies appear to be somewhat more stable, which for the latter can actually be confirmed with data from alternative surveys. An issue that is not subject to robustness checks here is the assumption of time-invariant norms. In technical terms, of course, it would be possible to generate time-varying measures of regional norm strength. On the other hand, although norms can indeed change over time, for this rather short period of investigation predetermined here, the

\footnotetext{
13 The full collection of norm measures obtained from five different social surveys and each correlation matrix showing conformity with the SOEP-based measures in Table 2 are available from the author upon request.

14 Note that, following the insights from above, these alternative estimations with social-beliefs proxies are carried out without additional interactions concerning the East-West disparity.

15 This can be observed when comparing the third (EB03) and the fourth measure (EB04) in Table 10 The idea behind these two measures is that the more interviewees consider disadvantaged people to be lazy, the stronger the normative pressure to not live on public funds. However, there is not even a truly significant correlation between these two "laziness" variables, so varying outcomes in the regression analysis are no surprise.
} 
assumption of time-invariance seems justified. ${ }^{16}$ An empirical analysis of norm evolution would require a much longer data set, which is not part of the research objectives here.

Finally, the validity of the norm measure at the individual level can and should be substantiated by some further checks. One may argue that the classification of norm violators includes too many individuals who may not be conscious of their non-compliance with the norm. Hence, in some final robustness checks, only those who individually reported receiving benefits are classified as living off other people. Despite the fact that this leads to a much smaller group of norm violators, the results do not change significantly. In this context, it is important to note that the old unemployment assistance was probably perceived in a similar way to ALG, i.e., as a type of insurance program linked to potentially lower stigma costs (see Bruckmeier and Wiemers 2012). Therefore, a reduction of the investigated time period seems justified to have a final look at the interactions between the different disutility determinants. The corresponding results overall underline the paper's argument (see Table 11 in the Appendix). Nevertheless, because of the above-described legal circumstances with respect to Germany's social system and subsequently smaller case numbers, the outcomes have to be handled with care, suggesting a definition of norm violation at the household level.

\section{Discussion}

The findings presented in this empirical study question the appropriateness of the standard approach in the research on the interplay of norm effects and unemploymentinduced unhappiness. Economic researchers argue that unemployed individuals are less negatively affected by aggregate unemployment than those who are employed. Sometimes it is even suggested that rising unemployment may have a positive impact on unemployed people's well-being, countering the negative effect of individual unemployment. Or, to put it another way, "Unemployment always hurts, but it hurts less when there are more unemployed people around" (Clark 2003, p. 346). However, using German panel data, regression results on the basis of the standard model cannot be regarded as consistent with such a social-norm hypothesis. Quite the contrary: the basic relationship is negative, which implies that the higher the regional unemployment rate is, the more distressing being unemployed is.

Although this conclusion may sound provocative or at least surprising to some, the investigation's findings can be reconciled with the existing literature. Actually, a very recent paper comes up with similar scepticism toward previous research, indicating that the line of argument here is becoming increasingly accepted among researchers. Using Swiss and German data, Oesch and Lipps (forthcoming) cannot find a mitigating effect of higher unemployment on unemployed people's well-being. Interestingly, they conclude that there may not be a social-norm effect in the described way, so that wellbeing might not be affected at all when "the stigma associated with living on welfare

\footnotetext{
16 Apart from this aspect, the more technical idea behind starting with data from 1999 is a change in how the household questionnaires ask interviewees about benefit receipts.
} 
benefits diminishes". In contrast, the paper here argues that there is indeed evidence for such a norm effect, but for this purpose it is necessary to actually look at the effects of living on benefits.

But how can other researchers find a positive interaction effect between the disutility caused by individual and aggregate unemployment, even when using data from the same German panel study? To achieve that, it is necessary to have the empirical analysis take no notice of the general disparity between East and West, implying the use of an undifferentiated model. However, as shown above, theoretical reasoning and empirical evidence suggest this kind of differentiation. In addition, the positive interaction effect can even then only be found when women are dropped from the sample, which is quite unsatisfactory when there is no theoretical foundation for such significant differentiation between the sexes and for the notion of a purely male norm effect. Finally, it is remarkable to note that this disparity between men and women almost disappears when analysing more recent data (see the last four columns of Table 11 in the Appendix), which leads to a third restriction for the standard social-norm effect to be found in the German data. However, even if all these conditions are kept, the positive outcome for the interaction between individual and aggregate unemployment is almost always insignificant. It therefore appears much more worthwhile to investigate norm effects by the analysis of the regionally varying disutility connected to benefit receipts.

Furthermore, the regression results presented here allow for a subsequent step, namely to actually calculate and interpret the regional differences in unemploymentinduced unhappiness and disutility from norm violation. By way of illustration, the OLS coefficients in the first column of Table 9 reveal that citizens in regions with a $20 \%$ unemployment rate lose on average about 0.6 points on the life-satisfaction scale from being unemployed. ${ }^{17}$ At the same time, with only $4 \%$ aggregate unemployment, the unemployment-caused drop in life satisfaction is about 0.4 points on the 11-point scale. Certainly, these differences in well-being reductions for unemployed individuals are much more pronounced when the East-West disparity is considered. According to the results in the first column of Table 6, the same gap in unemployment rates (in one of the two former halves of Germany) would make a difference of almost 0.6 points on the life satisfaction scale.

Beside this unhappiness-increasing effect experienced in economically weak regions, those living off public funds simultaneously experience a reduction in their misery, which is commonly referred to as the social-norm effect. In other words, disutility from being in non-compliance with the norm against living off other people is smaller when regional economic conditions are worse, which usually goes along with a weaker normative pressure to earn one's own income, making the individual misfortune easier to put up with. Note that the latter disutility effect is generally much smaller, so that non-compliance with the social norm in states with weak norms might even be negligible to people's well-being. Based on the OLS coefficients from the first column in Table 6, in which the disparity between East and West is considered, the outcome for norm violation in Bremen is even slightly positive. Hence, while the

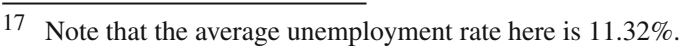


unemployed suffer strongly from high levels of unemployment and the consequent bad job prospects, they basically do not suffer from living off other people, which can be linked to weak normative pressure. On the other hand, being one of the few Bavarians in non-compliance with the social norm causes on average considerable well-being reductions of almost 0.3 points. As a matter of course, this apparent disadvantage is outweighed for unemployed individuals who benefit from better job prospects in Bavaria.

These insights lead to the issue of labour market policies. Economic researchers regard empirical evidence for a social-norm effect as a contribution in explaining unemployment hysteresis. In fact, the argument for a strong association between normative pressure to earn one's income and regional economic conditions is confirmed in this study. Moreover, the relationship between unemployment-induced unhappiness and willingness to work is empirically valid, so that smaller reductions in well-being indeed go along with less motivation to search for employment (Chadi 2010). However, with regard to the discussion of the empirically indisputable, but theoretically less well substantiated, phenomenon of multiple unemployment equilibria, the aspect of employment prospects must definitely be considered. In sum, it may well be that the two factors, changing job opportunities and social-norm effect, outweigh each other in regard to the overall utility effect. Hence, even if the results are interpreted in such a manner that ceteris paribus reductions in norm strength may contribute to the social problem of unemployment, the findings make clear that every increase in unemployment due to weaker norms simultaneously leads to lower well-being among unemployed individuals, which counters and therefore limits the contribution of the social-norm effect in explaining unemployment.

Nevertheless, social norms in the labour market must be taken seriously. For example, the analysis of the interplay between disutility effects from living off other people and employment status is very revealing for the discussion of labour market concepts. Imagine that policymakers would like to promote a low-wage sector with jobs that are subsidised, if necessary, with additional payments from public funds. The success of such a policy would be at risk when the people in those jobs experience significant reductions in well-being from non-adherence to the social norm against living off other people.

The findings presented here will hopefully contribute to the growing field of research on social norms connected to the labour market. While this study is based on German data, it must be noted that, just as there are significant differences between East and West Germany, the results can be very different in other regions of the world. Most recently, researchers have started to compare unemployment-induced unhappiness and related norm effects on a cross-national basis (see Stavrova et al. 2011). Hence, the findings here are first and foremost representative of the German people. It could very well be that the aspect of reduced job prospects is less important to unemployed individuals in other countries, so that the social-norm effect may indeed prevail, just as has been suggested in previous studies. 


\section{Conclusion}

This study is aimed at the identification of the true relationship between the disutility determinants individual and aggregate unemployment, at least for the people of Germany, while simultaneously yielding evidence for a social-norm effect. The basic idea of distinguishing unhappiness from living off other people and unhappiness caused by unemployment makes it possible to address the problem of two countering effects. A person's own non-compliance with the norm against living off public funds is easier to bear when more people in the reference group also deviate from the norm. While this has a mitigating effect on people's unhappiness, there is another effect capable of countering it and thus potentially outweighing any positive impact. This disutility effect from higher unemployment can be linked to the worsening job prospects, from which unemployed people might suffer considerably.

In this paper, it is argued that with respect to the analysis of employment-related effects on well-being, it is necessary to consider the enormous disparity between East and West Germany that persists socially and empirically even after more than one decade of reunification. As a consequence, it seems difficult to find evidence for a social-norm effect of unemployment in the way that it is described in the literature, which is all the more reason to refer to the original definition of the social norm against living off other people and to investigate disutility effects from dependency on public funds.

This study's period of investigation is deliberately short and was selected to clarify how to actually measure norm effects, which arguably has not been done accurately in the existing literature. A better understanding of the social norm against living off public funds should allow future research to address such issues as the development of norm effects by use of longer data sets. Such investigations may also be particularly promising for Germany, with its differently socialised cohorts of labour market participants.

Acknowledgements The author is grateful to Daniel Arnold, Tobias Böhm, Daniel Chen, Clemens Hetschko, Andreas Knabe, Tobias Pfaff, Ronnie Schöb, Mark Trede, Ulrich van Suntum, the anonymous referees as well as the participants of the 7th International SOEP Symposium, the HEIRs conference on markets and happiness and seminars at the University of Muenster for valuable comments and advice.

\section{Appendix}

See Tables 7, 8, 9, 10, 11. 


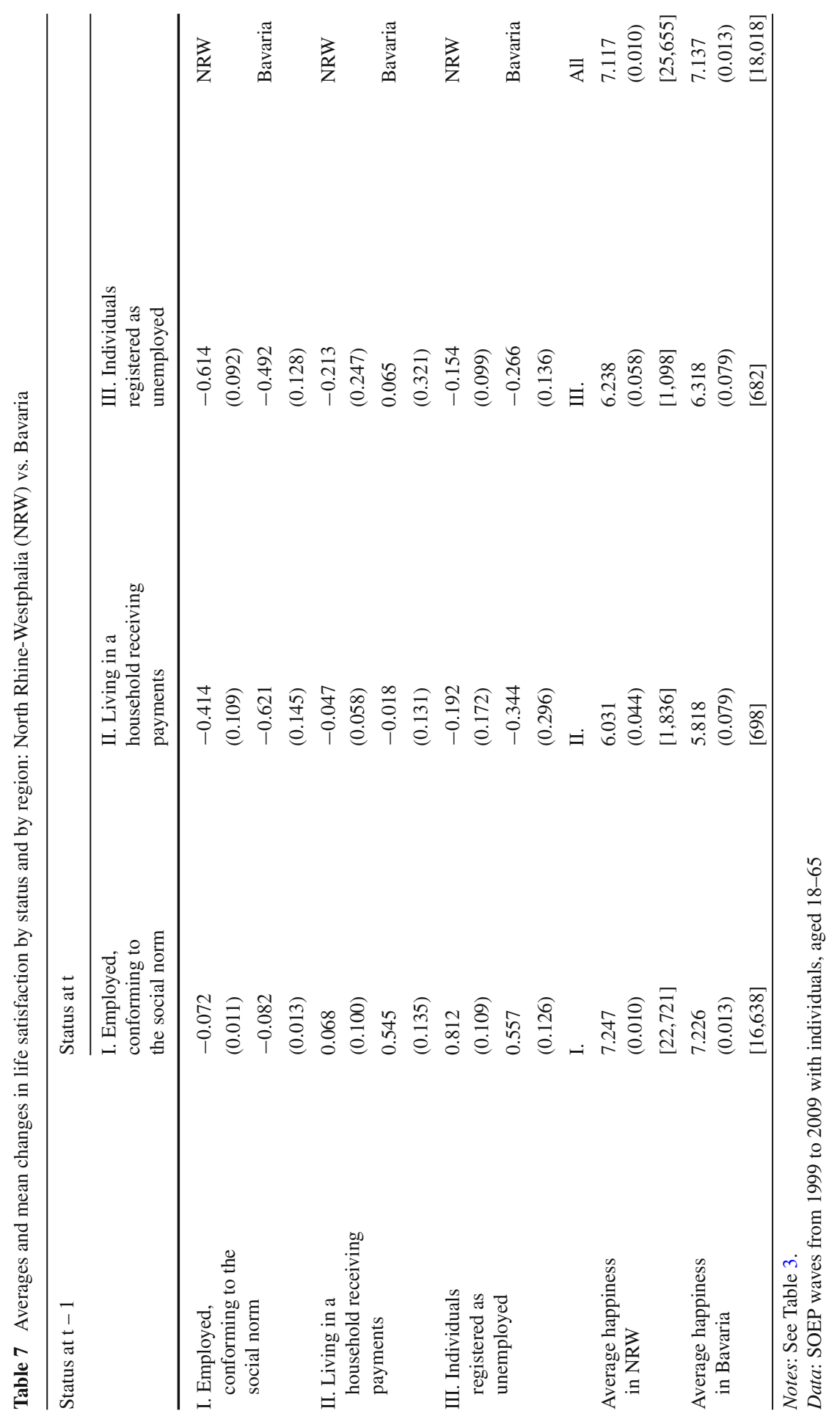




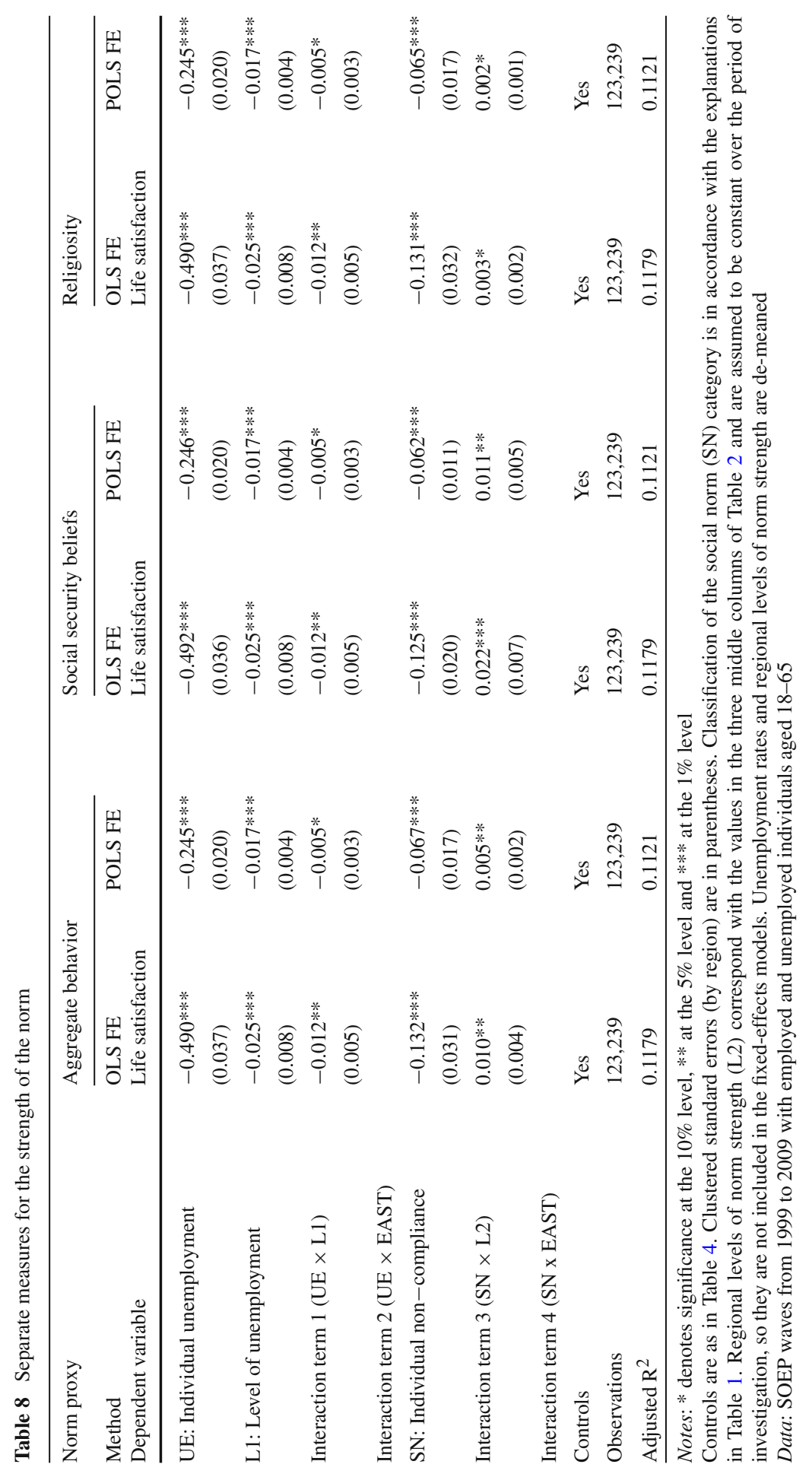




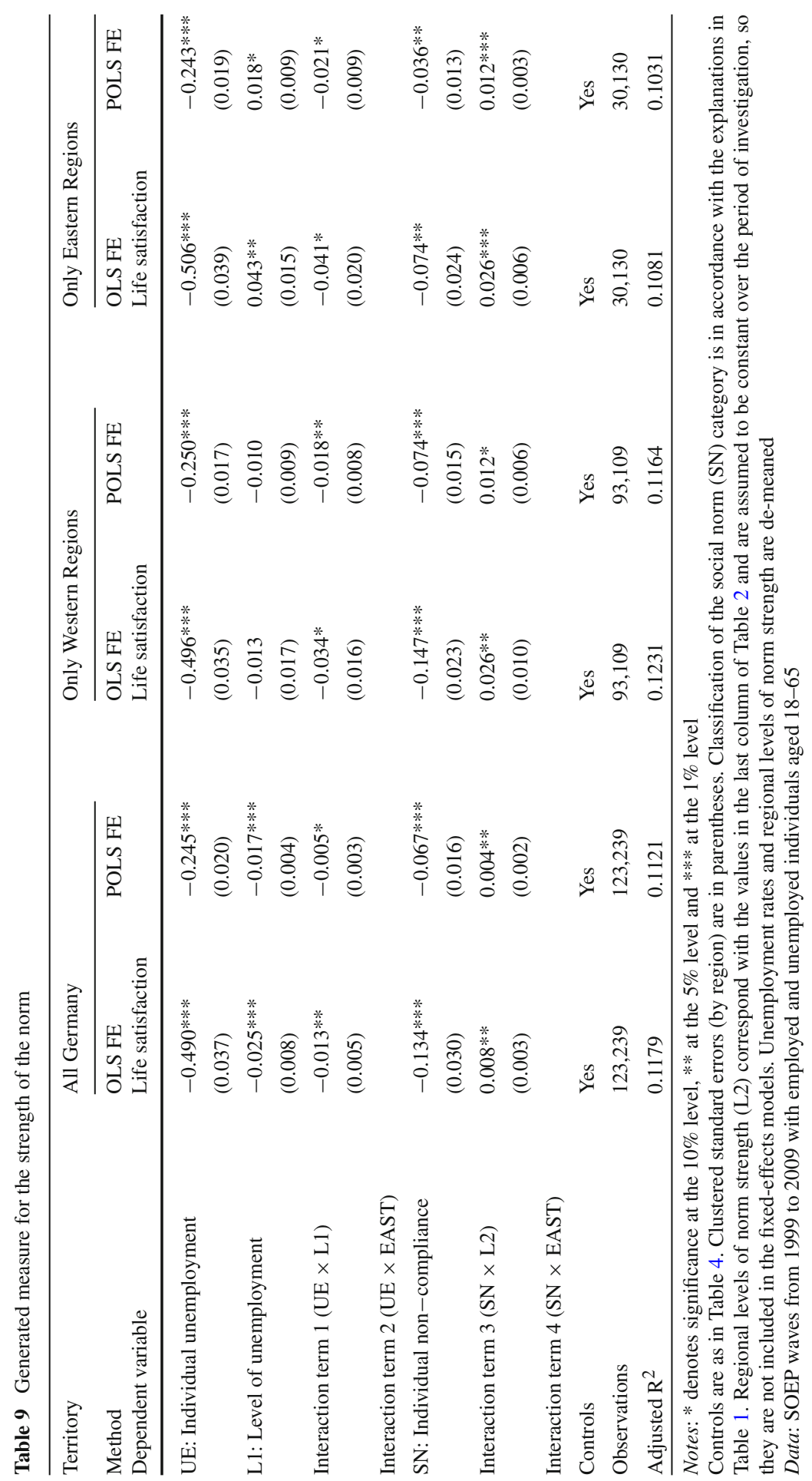




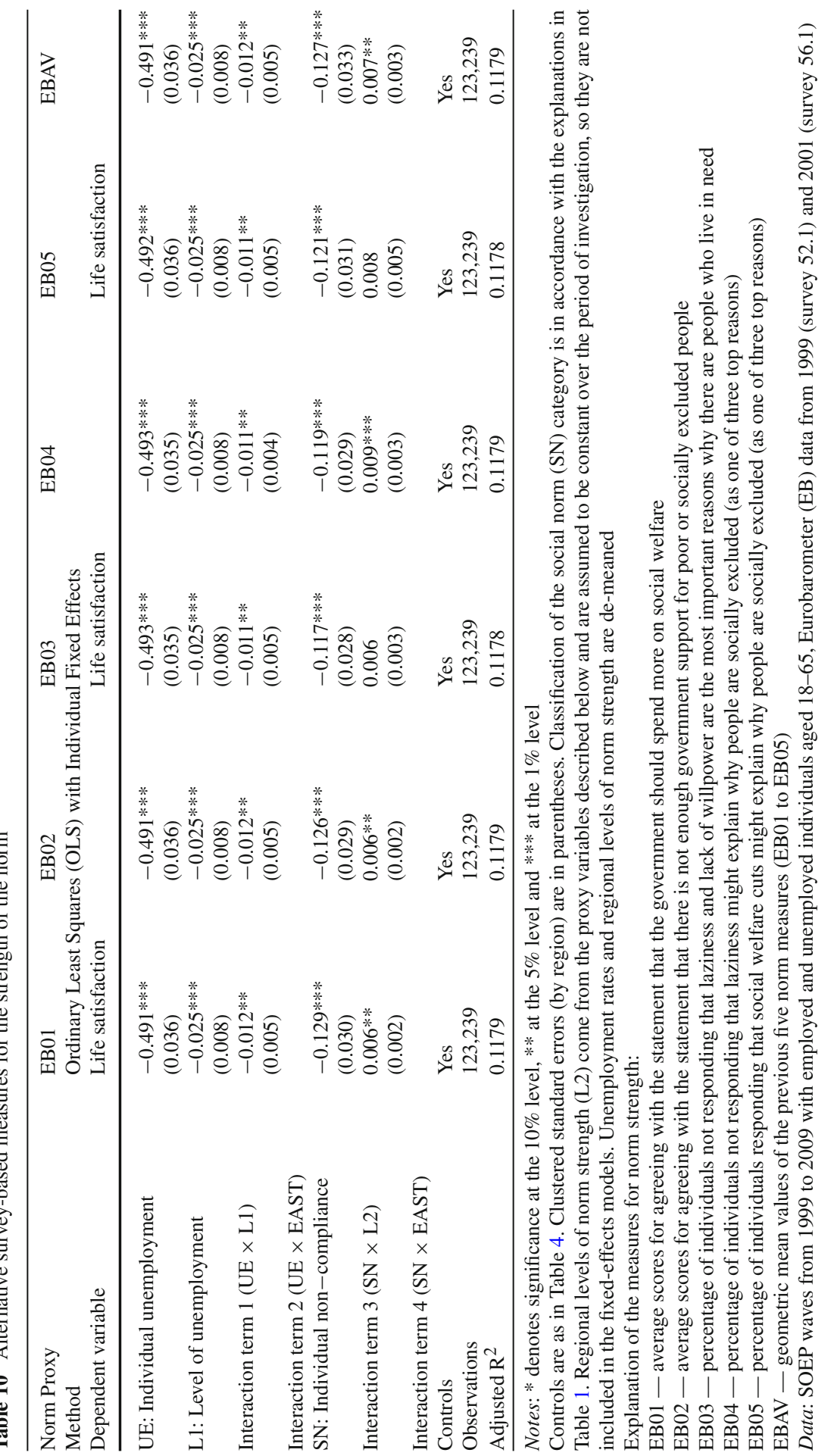




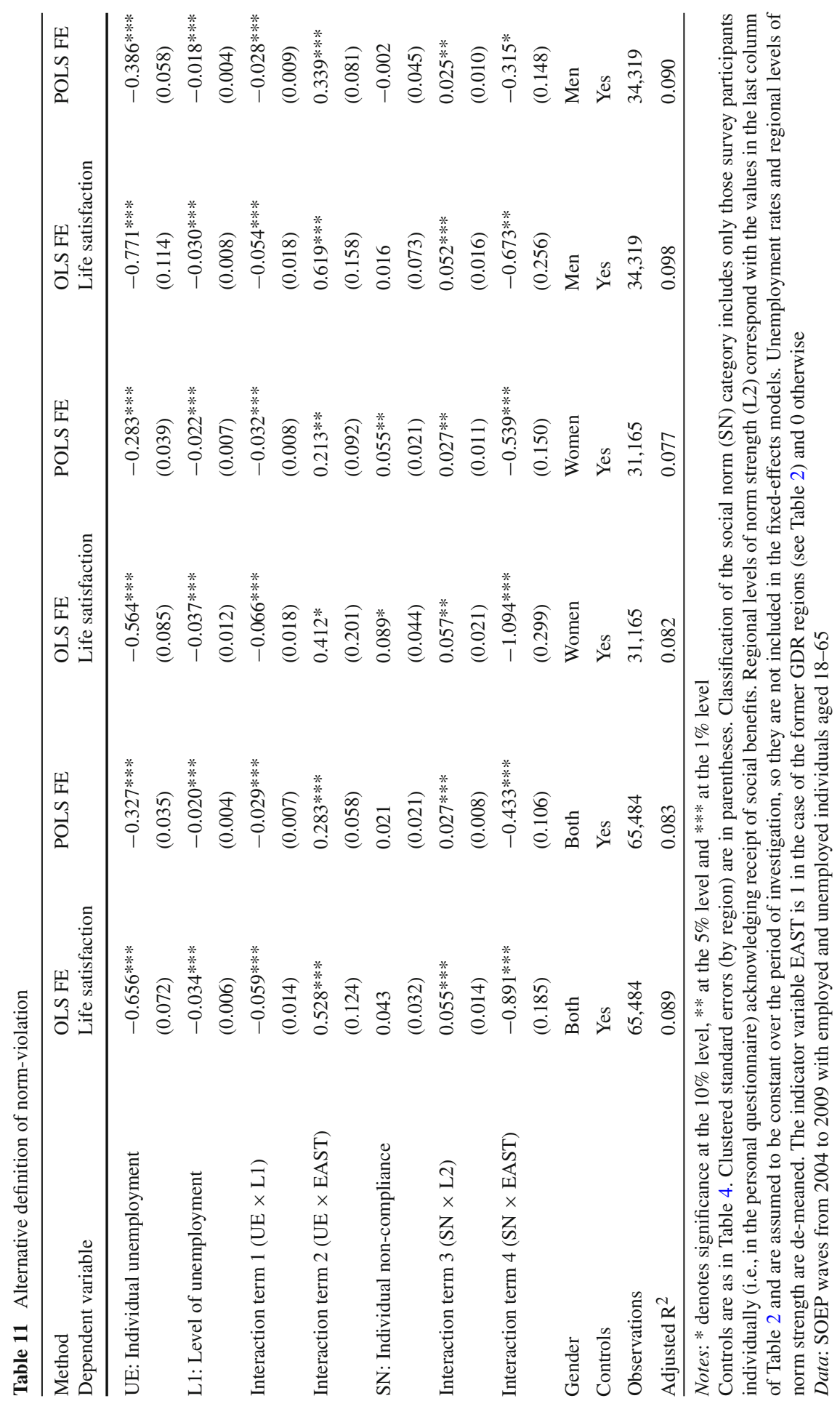




\section{References}

Ai C, Norton EC (2003) Interaction terms in logit and probit models. Econ Lett 80:123-129

Alesina A, Fuchs-Schündeln N (2007) Good-bye Lenin (or not?): the effect of communism on people's preferences. Am Econ Rev 97:1507-1528

Alm J, Torgler B (2006) Culture differences and tax morale in the United States and in Europe. J Econ Psychol 27:224-246

Bruckmeier K, Wiemers J (2012) A new targeting: a new take-up? Non-take-up of social assistance in Germany after social policy reforms. Empir Econ 43:565-580

Carroll N (2007) Unemployment and psychological well-being. Econ Rec 83:287-302

Chadi A (2010) How to distinguish voluntary from involuntary unemployment: on the relationship between willingness to work and unemployment-induced unhappiness. Kyklos 63:317-329

Chadi A (2012) Employed but still unhappy? On the relevance of the social work norm. J Appl Soc Sci Stud (Schmollers Jahrbuch) 132:1-26

Clark AE (2003) Unemployment as a social norm: psychological evidence from panel data. J Labor Econ 21:323-351

Clark AE, Oswald AJ (1994) Unhappiness and unemployment. Econ J 104:648-659

Clark AE, Knabe A, Rätzel S (2009) Unemployment as a social norm in Germany. J Appl Soc Sci Stud (Schmollers Jahrbuch) 129:251-260

Clark AE, Knabe A, Rätzel S (2010) Boon or bane? Others' unemployment, well-being and job insecurity. Labour Econ 17:52-61

De Neve JE, Christakis NA, Fowler JA, Frey BS (2012) Genes, economics, and happiness. J Neurosci Psychol Econ 5:193-211

Di Tella R, MacCulloch RJ, Oswald AJ (2001) Preferences over inflation and unemployment: evidence from surveys of happiness. Am Econ Rev 91:335-341

Di Tella R, MacCulloch RJ, Oswald AJ (2003) The macroeconomics of happiness. Rev Econ Stat 85:809_ 827

Elster J (1989a) Social norms and economic theory. J Econ Perspect 3:99-117

Elster J (1989b) The cement of society. Cambridge University Press, Cambridge

Ferrer-i-Carbonell A, Frijters P (2004) How important is methodology for the estimates of the determinants of happiness? Econ J 114:641-659

Frey BS (2008) Happiness: a revolution in economics. MIT Press, Cambridge

Frey BS, Stutzer A (2002) Happiness and economics: how the economy and institutions affect well-being. Princeton University Press, Princeton

Frey BS, Stutzer A (2005) Happiness research: state and prospects. Rev Soc Econ 62:207-228

Frijters P, Haisken-DeNew JP, Shields MA (2004) Money does matter! Evidence from increasing real income and life satisfaction in East Germany following reunification. Am Econ Rev 94:730-740

Heinemann F (2008) Is the welfare state self-destructive? A study of government benefit morale. Kyklos 61:237-257

Kassenboehmer S, Haisken-DeNew JP (2009) Social jealousy and stigma: negative externalities of social assistance payments in Germany. Ruhr economics papers no. 117, Department of Economics, University of Bochum, Bochum

Knabe A, Rätzel S (2011) Scarring or scaring? The psychological impact of past unemployment and future unemployment risk. Economica 78:283-293

Lindbeck A (1995) Welfare state disincentives with endogenous habits and norms. Scand J Econ 97:477-494

Lindbeck A, Nyberg S (2006) Raising children to work hard: altruism, work norms, and social insurance. Q J Econ 121:1473-1503

Luechinger S, Meier S, Stutzer A (2010) Why does unemployment hurt the employed? Evidence from the life satisfaction gap between the public and the private sector. J Hum Res 45:998-1045

Lykken D, Tellegen A (1996) Happiness is a stochastic phenomenon. Psychol Sci 7:186-189

Oesch D, Lipps O (forthcoming) Does unemployment hurt less if there is more of it around? A panel data analysis for Germany and Switzerland. Eur Sociol Rev

Powdthavee N (2007) Are there geographical variations in the psychological cost of unemployment in South Africa? Soc Indic Res 80:629-652

Shields MA, Wheatley Price S (2005) Exploring the economics and social determinants of psychological well-being and perceived social support in England. J R Stat Soc A 168:513-537 
Shields MA, Wheatley Price S, Wooden M (2009) Life satisfaction and the economic and social characteristics of neighbourhoods. J Popul Econ 22:421-443

Stavrova O, Schlosser T, Fetchenhauer D (2011) Are the unemployed equally unhappy all around the world? The role of the social norms to work and welfare state provision in 28 OECD countries. J Econ Psychol 32:159-171

Stutzer A, Lalive R (2004) The role of social work norms in job searching and subjective well-being. J Eur Econ Assoc 2:696-719

Torgler B (2005) A knight without a sword? The effects of audit courts on tax morale. J Inst Theor Econ 161:735-760

Van Praag BMS, Ferrer-i-Carbonell A (2008) Happiness quantified: a satisfaction calculus approach (revised edn). Oxford University Press, Oxford

Wagner G, Frick J, Schupp J (2007) The German socio-economic panel study (SOEP): scope, evolution and enhancements. J Appl Soc Sci Stud (Schmollers Jahrbuch) 127:139-169

Winkelmann L, Winkelmann R (1998) Why are the unemployed so unhappy? Economica 65:1-15

Young HP (2008) Social norms: the new Palgrave dictionary of economics. Macmillan, London 